\title{
CASTELO DA MATEMÁGICA: UM ADVENTURE TEXTUAL APLICADO AO ENSINO
}

\author{
Tiago Custódio Franco ${ }^{1}<$ tiago_franck@ hotmail.com> \\ Fabiana Lorenzi ${ }^{1}<$ fabilorenzi@gmail.com $>$ \\ André Peres ${ }^{2}<$ andre.peres@ poa.ifrs.edu.br> \\ ${ }^{1}$ Universidade Luterana do Brasil (ULBRA) - Curso de Ciência da Computação - Campus Canoas \\ Av. Farroupilha, 8001 - Canoas - RS \\ ${ }^{2}$ Instituto Federal de Educação, Ciência e Tecnologia do RS - Campus Porto Alegre \\ Rua Coronel Vicente, 281 - Porto Alegre - RS
}

\begin{abstract}
RESUMO
Este artigo descreve o desenvolvimento do Castelo da Matemágica: um jogo educacional do gênero adventure em texto, voltado para o ensino, que permite ao professor visualizar o desempenho do aluno. O jogo proposto faz uso de ontologias para seu funcionamento e foi validado no ensino de matemática.
\end{abstract}

Palavras-chave: Jogo educativo, Adventure textual, ontologias.

\section{ABSTRACT}

Title: "Preparation of a Text Adventure for teaching"

This paper describes the development of Castelo da Matemágica: an educational adventure game genre in text for teaching, which allows teachers to view student performance. The proposed game makes use of ontologies for its operation and has been validated in math teaching

Key-words: Educational game, Text Adventure Games, Ontologies.

\section{INTRODUÇÃO}

No cenário atual, tecnologicamente desenvolvido, há certa preocupação em encontrar métodos atrativamente eficazes para o ensino. Pode-se dizer que os alunos da atualidade já nasceram sob grande influência tecnológica, desde a babá eletrônica até celulares e redes sociais. Desta forma uma nova plataforma de ensino, capaz de usufruir da potência da contemporaneidade tecnológica, é necessária para acompanhar esta tendência, sendo eficaz no quesito aprendizado.

Os jogos, sejam quais forem, desde muito antes das redes sociais (tão ativas entre os jovens), são grandes socializadores, quando em grupos ou duplas, pois promovem a interação. Também são desenvolvedores de raciocínio, capazes de serem pedagogicamente inseridos no contexto das atividades escolares, tornando o aprendizado fluído e divertido, associando o conteúdo programático à boas lembranças, estimulando desta forma a cognição, por envolver memória, imaginação, percepção e raciocínio.

Baseado nas oportunidades que os jogos educacionais oferecem neste campo, a proposta apresentada neste artigo consiste na modelagem de um jogo educacional, podendo ser aplicado a diversas matérias, apresentando tópicos relacionados à matéria. Para fins de validação do jogo que foi desenvolvido, a matemática foi utilizada como tema principal do ambiente, onde a criança é avaliada pelo seu desempenho ao realizar diferentes enigmas, que serão apresentados em níveis progressivos de dificuldade.

O jogo desenvolvido é do gênero adventure de texto, onde o andamento do jogo se dá por meio de ações a serem informadas pelo jogador. Sendo assim uma ferramenta para causar 
maior imersão do aluno no jogo, criando uma história a ser traçada e percorrida por um enredo envolvente e bem-humorado, podendo ter traços fantasiosos diversos dependendo da faixa etária e disciplina (conteúdo) envolvida.

Este artigo está estruturado da seguinte forma: na seção 2 são apresentados os assuntos correlatos, inclusive as tecnologias e técnicas utilizadas, seguido da apresentação do desenvolvimento de um protótipo e suas características na seção 3. As validações realizadas no protótipo são apresentadas na seção 4.

\title{
2 REFERENCIAL TEÓRICO
}

Esta seção diz respeito aos assuntos relacionados ao desenvolvimento do aplicativo, tais como suas áreas de interesse e aplicações, bem como a tecnologia utilizada para seu funcionamento.

\subsection{Jogos educativos}

Dado o momento de alto grau tecnológico, exposto às crianças contemporaneamente, uma forma diferenciada de aprendizado torna-se interessante aos olhos de educadores.

\begin{abstract}
"Os Jogos educativos possibilitam ao aluno aprender de forma natural, prazerosa e dinâmica, porque traz desafios que despertam na criança o interesse na busca dos conhecimentos, além de oferecer um maior envolvimento social entre os alunos, bem como a formação de conceitos éticos, de solidariedade, de regras, de trabalho em grupo, de respeito mútuo, etc.(NICOLETTI e FILHO, 2004)"
\end{abstract}

Tais jogos devem seguir determinadas diretrizes, para que sejam plenamente aproveitados pelos professores e alunos, estimulando a criança a resolver problemas. Igualmente ajudando no desenvolvimento do pensamento lógico, requerido pelo adventure, que por ser lúdico aumenta as chances de inserção e satisfação, por parte do jogador.

Conforme GROENWALD e TIMM (2000); Os jogos trabalhados em sala de aula devem ter regras e são classificados em determinados tipos, dentre eles destaca-se o jogo do tipo estratégico; Onde são trabalhadas habilidades de raciocínio lógico, havendo leitura de regulamento e busca de caminhos para que seja atingido o objetivo final, no qual os alunos utilizam determinadas estratégias para isso. $\mathrm{O}$ fator sorte não interfere no resultado, sendo somente resultado das escolhas tomadas pelos jogadores.

Para MORATORI (2003), os jogos devem representar um desafio, capaz de instigar a vontade de jogar, por parte do aluno. Deve ter uma atmosfera agradável, para que eles participem ativamente.

Segundo (LIMA et al, 2009), outra pesquisa na área foi uma entrevista a professores alfabetizadores do "MAIS" (Projeto Movimento de Aprendizagens Interativas), da Rede Municipal do Recife, onde desde 2005 o uso de jogos, como ferramentas educacionais vem sendo estudado. Em suas respostas os docentes acreditam que os jogos têm o papel de auxiliar o processo de aprendizagem dos alunos, nos aspectos cognitivos, afetivos e sociais, tornando o processo de estudo e aprendizado algo mais prazeroso.

Em pesquisa realizada por ARAÚJO (2000), foram relatadas experiências utilizando atividades lúdicas em sala de aula para o aprendizado de matemática. Neste relato a autora detalha os resultados obtidos em turmas de primeira a quarta série buscando desmitificar a 
matemática para os alunos. Destaca-se nestas turmas a da quarta série que, por meio de uma brincadeira utilizando gráficos, despertou interesse em estatística e pesquisas de opinião, levando os alunos a fazerem experiências, com pesquisas de intenção de voto em sua cidade.

Em (PIERINI et al, 2012) os autores apresentam um jogo aplicado para o aprendizado de conjuntos numéricos. O jogo foi elaborado a partir de imagens bidimensionais (2D), tendo sua classificação como híbrido, sendo composto de elementos diferentes em cada fase, onde a história se alterna entre ações de reflexos rápidos e elementos de narrativa.

\subsection{Adventures}

Adventures são um gênero de jogos computacionais. Seu nome é derivado da língua inglesa, cuja tradução livre é "aventura". De acordo com JERZ (2001), em meados de 1970, o primeiro adventure conhecido foi criado por um programador e explorador de cavernas amador chamado Will Crowther. Foi construído como forma de interagir com seus filhos. Crowther criou um jogo completamente em texto narrando uma exploração em uma caverna, contando com um "narrador" que falava sentenças completas, entendendo construções simples de duas palavras que se aproximavam do inglês natural.

Um adventure textual é uma história interativa, tal como dito por GRANADE (2010) é comparável a ler um livro cujo próprio leitor diz que ações o protagonista deve tomar. Embora alguns jogos deste gênero possam apresentar gráficos, a ambientação maior se dá por conta da imaginação do jogador. Outros elementos comuns a esses jogos incluem interações específicas com objetos descritos na história, uma série de salas (ou quebra cabeças em sequência) que deve ser percorrida para vencer o jogo e temáticas variadas, podendo variar entre ficção científica, fantasia ou realismo.

\subsubsection{Adventures na educação}

Sobre as aplicações dos adventures na educação, em (CAVALLARI et. Al, 1992) os autores aconselham utilizar o adventure integrado às atividades normais de sala de aula, ou seja, utilizá-lo como material de apoio, como exercícios de fixação de conteúdo.

A respeito de usos deste tipo de jogo em sala de aula GRANADE (2010) descreve a utilidade do jogo Dracula's Castle, de Al Staffieri, para auxiliar o ensino de inglês como segunda lingua.

Outra aplicação relacionada ao adventure foi apresentada em (LOPES et al, 2002) no projeto AULATIVA. Os autores utilizaram um método de jogo que consistia em troca de emails (PbEM) (BITTENCOURT e GIRAFFA, 2003), com o objetivo de ensinar geografia e história para alunos de quinta e sexta série. Os professores enviavam a descrição da história (com várias informações didáticas) e, logo após, o aluno enviava a sua ação, que seria interpretada pelo mestre do jogo e dar continuidade ao jogo.

\section{Castelo da matemágica}

Esta seção apresenta os detalhes de desenvolvimento do Castelo da Matemágica, descrevendo e exemplificando suas características e funcionamento.

\subsection{Escopo}

Este artigo apresenta o adventure textual "Castelo da Matemágica". Neste jogo, o jogador assume o papel de um explorador que entra em um misterioso castelo, solucionando enigmas matemáticos a cada sala.

Os conteúdos matemáticos apresentados no jogo foram previamente classificados em três diferentes temas: regra de três, área/perímetro e ângulos. Estas questões foram elaboradas 
com o apoio de professores de matemática.

Cada questão tem um número possível de ações mapeadas que, quando informadas pelo aluno, resultarão em alguma consequência no jogo. Cada ação pode aumentar ou diminuir a pontuação final do aluno ou revelar dicas sobre como resolver o problema matemático apresentado. A figura 1 exibe o fluxograma utilizado neste jogo:

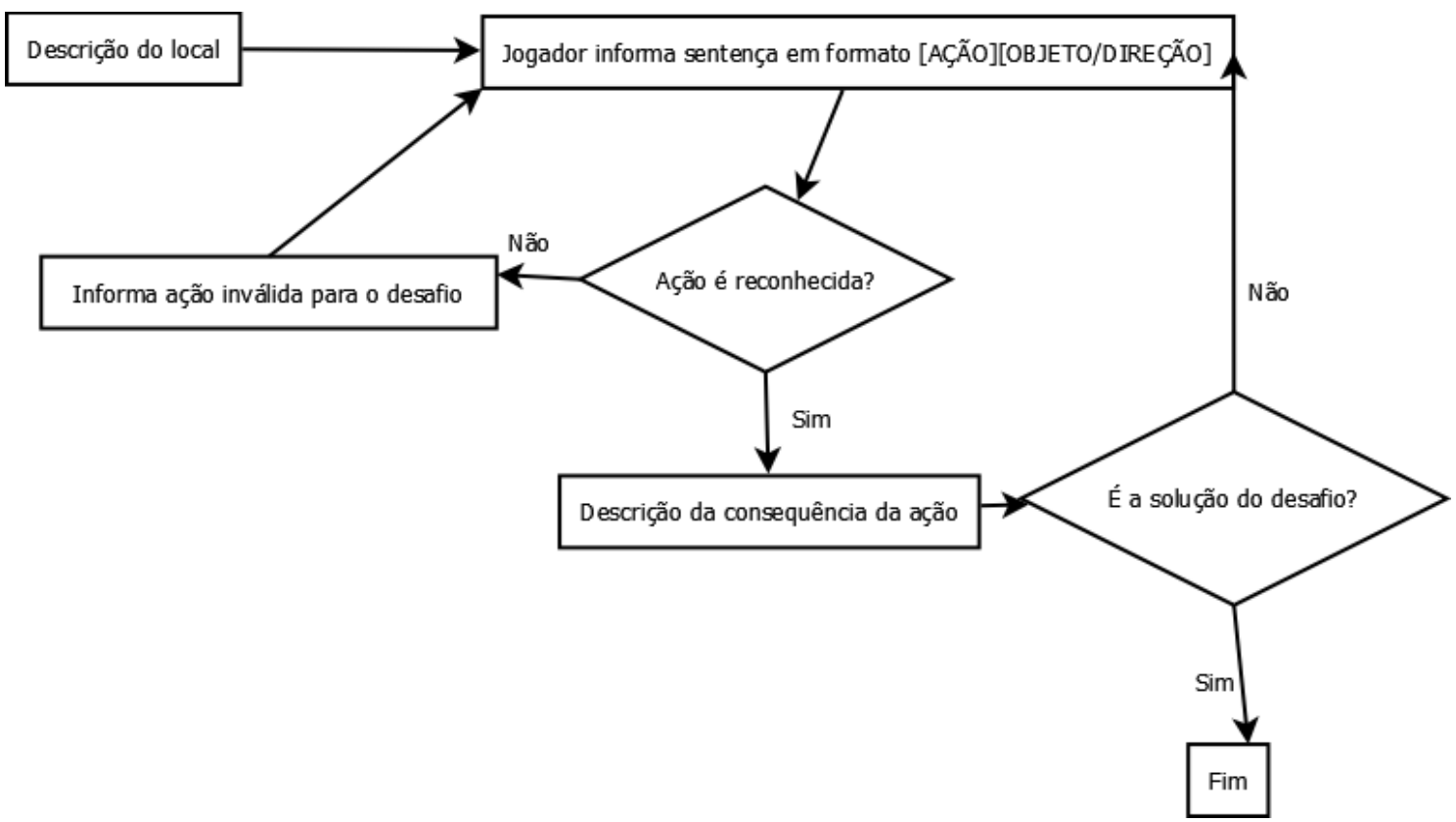

Figura 1 - Fluxograma de um desafio do adventure

O jogo fornece ao jogador uma descrição do local em que ele se encontra. Ao informar a ação realizada, o jogo faz um reconhecimento desta ação e retorna uma consequência apropriada. Todo este processamento é feito com base em ontologias, banco de dados e seus resultados são exibidos em uma interface web. O detalhamento destes itens se dará nas próximas subseções.

\subsection{Elaboração da Ontologia}

A ontologia utilizada neste jogo foi elaborada no aplicativo Protegé 4.3.0, sendo acessada e manipulada por meio da OWL API, disponível para a linguagem de programação Java.

Seu desenvolvimento buscou separar e classificar os elementos disponíveis no jogo, resultando em uma árvore de significados que classifica todos os elementos mapeados agrupando-os por sinônimos. A figura 2 demonstra as superclasses da Ontologia. Os componentes do jogo podem ser classificados como sendo algum tipo de ação (verbos no formato infinitivo que indicam uma ação a ser tomada), direção (esquerda, direita, acima, abaixo, etc.) ou elemento (que podem ser um objeto, lugar, personagem ou medida).

Esta ontologia pode ser acessada pela OWL API da linguagem Java para verificar se uma expressão informada pelo jogador é válida e, em caso positivo, qual será o retorno dela. Para exemplificar isto, será utilizada a frase "Vou olhar aquela porta" como exemplo. A figura 3 exibe os componentes que serão percorridos a fim de buscar esta expressão. Os elementos com círculos são chamados de classes da ontologia. Os itens com losangos provenientes destas classes são denominados de indivíduos. Para melhor visualização os termos "olhar" e "porta" estão separados de seus indivíduos semelhantes. 


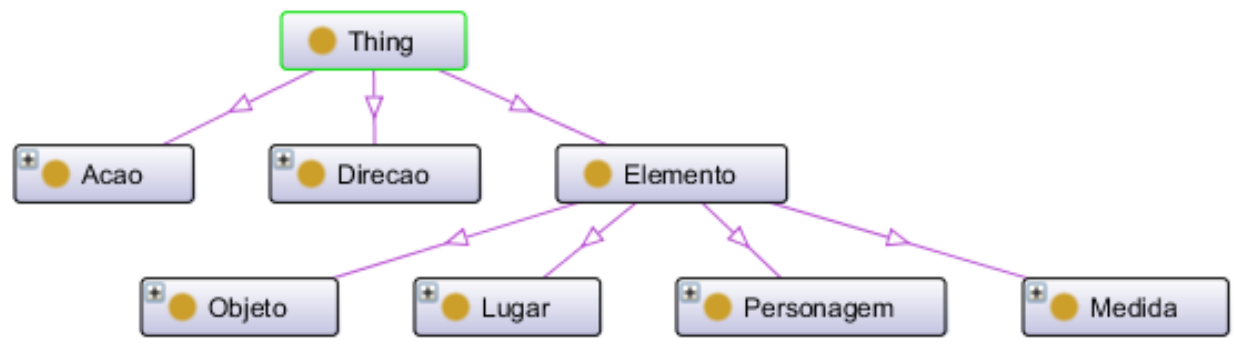

Figura 2 - Ontologia e suas superclasses

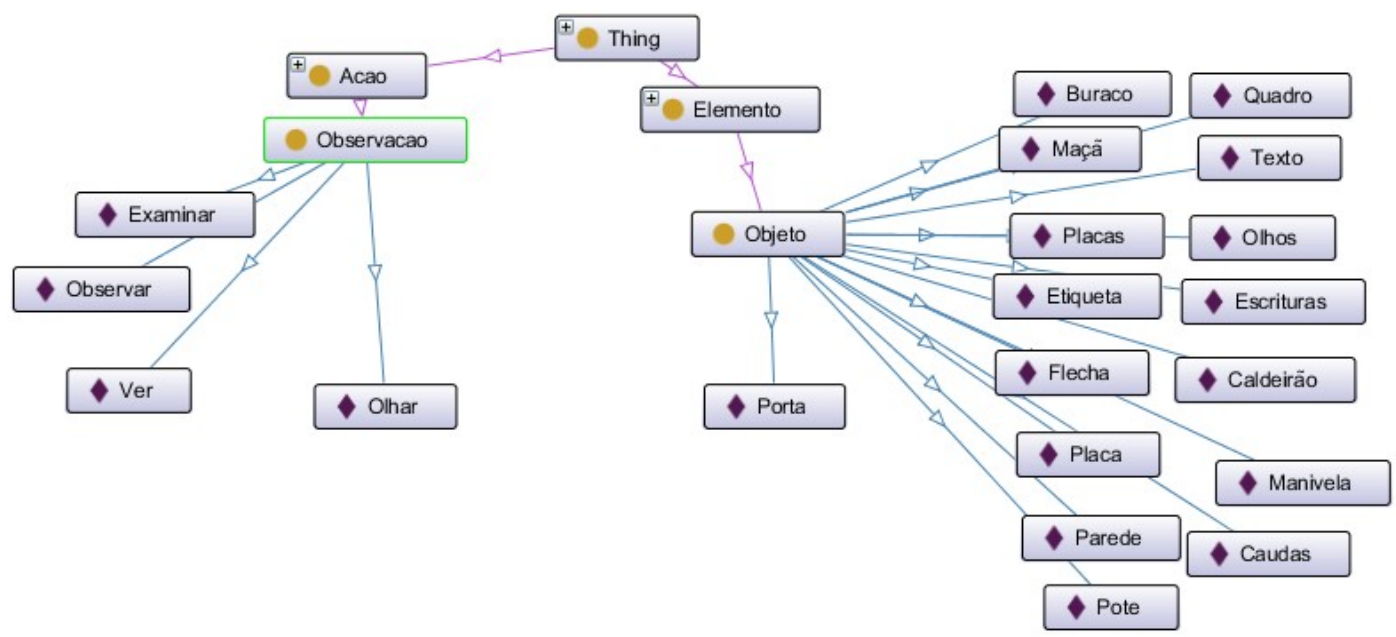

Figura 3 - Localizando expressão "Vou olhar aquela porta" na ontologia

Seguindo o exemplo, o jogo interpretará que a frase "Vou olhar aquela porta" representa a expressão \#Observação\#Objeto. Entretanto, não é interessante para o jogo simplesmente retornar a classe Objeto, visto que as salas do jogo podem conter muitos objetos. Para tanto, o jogo foi desenvolvido de forma que, caso encontre um termo na ontologia que não seja da superclasse Ação, será retornado seu próprio nome. Sendo assim, a expressão a ser retornada será \#Observação\#Porta, indicando que o jogador descreveu uma ação de observação no objeto porta. Números são considerados na expressão retornada. Por exemplo, se a frase informada pelo jogador for "Vou Olhar a porta 5", será retornada a expressão \#Observação\#Porta\#5.

É importante frisar que palavras que não constam na ontologia, tais como verbos fora do formato infinitivo, pronomes, adjetivos e artigos serão ignorados pelo adventure nesta primeira versão desenvolvida. Todas as expressões válidas para cada desafio do jogo estão armazenadas em um banco de dados (desenvolvido na plataforma My SQL).

\subsection{Camada web}

Para a utilização do jogo, foi criada uma aplicação web utilizando o framework Spring MVC em conjunto com o servidor glassfish 3.1.

A figura 4 apresenta o layout do adventure que foi construído em um estilo medieval para ambientar o jogador no mundo do jogo. À esquerda está o banner do jogo e à direita está um "pergaminho" que armazena todas as etapas anteriores da fase. Sua posição é justificada por 
questões de usabilidade, pois evita que o jogador tenha que usar a barra de rolagem da página para poder ler o que aconteceu em etapas anteriores da fase. Evitando que a tela saia de seu foco principal, que é seu conteúdo central.

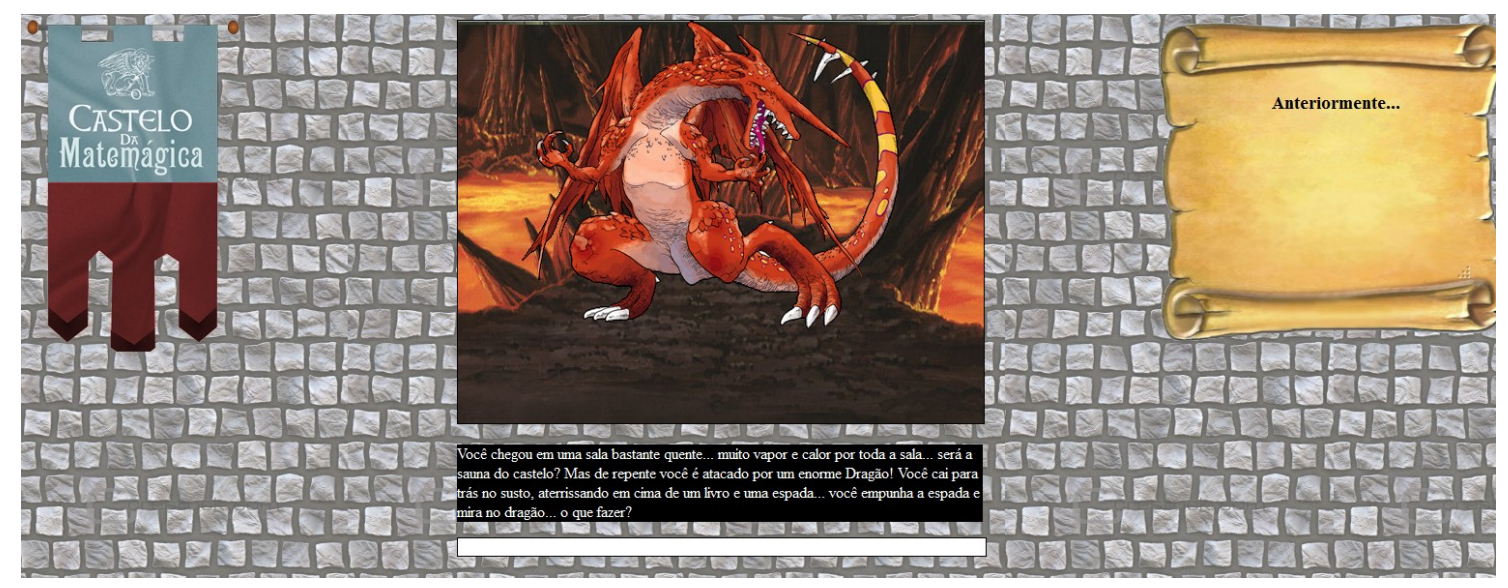

Figura 4 - Interface gráfica do jogo "Castelo da Matemágica"

No centro da página está a imagem correspondente da fase atual e sua descrição. $\mathrm{O}$ campo que exibe as imagens é um campo do tipo canvas. Elemento do HTML5 que permite diversas imagens sobrepostas, este efeito auxilia as variações de imagens das etapas e efeitos de transição entre as mesmas. Logo abaixo ao campo de descrição da fase está o campo de resposta. O jogador deve informar neste campo que ação será tomada. Ao digitar uma ação, é enviada ao servidor uma requisição AJAX que tem como parâmetros o id da fase atual e a frase enviada. Após a requisição ser recebida, o jogo faz o processamento de identificar se a frase recebida é uma expressão válida para a fase atual e retorna o resultado correspondente.

Após receber a resposta da chamada AJAX, a página poderá trocar o texto da fase atual e trocar a sua imagem, se uma URL for informada. No caso de ocorrer término da fase, o campo de resposta é desabilitado e será solicitado ao jogador que siga para a próxima fase, clicando em um botão.

Tendo em vista facilitar os processos empregados no jogo, alguns módulos adicionais foram desenvolvidos e disponibilizados via web. São eles:

- Cadastro de turmas: módulo que deve ser acessado por um professor, onde é possível cadastrar sua turma fornecendo um nome para a mesma. Turmas cadastradas poderão ser escolhidas pelos jogadores no momento de cadastro;

- Relatório de desempenho: os professores têm a possibilidade de acessar os históricos de alunos de sua turma, onde é permitido visualizar o que os seus alunos digitaram durante as espatas do jogo, e assim conseguir efetuar análises de desempenho de seus alunos.

\section{VALIDAÇÃO DO PROTÓTIPO}

A validação do jogo foi realizada através de um beta-test e da aplicação de um questionário aos professores. Nesta validação foram avaliados os aspectos visuais e funcionais do jogo, visando buscar um feedback de sua interação e avaliar sua utilidade como ferramenta facilitadora de ensino.

\subsection{Caracterização da amostra}

A amostra foi dividida em dois grandes grupos: matemática e computação. O segmento 
da computação foi composto por duas turmas universitárias do curso de Ciência da Computação, uma contendo 35 alunos de segundo semestre e 32 alunos de sexto semestre. A outra fração da amostra, por parte da computação, foi composta por 31 alunos voluntários do curso de computação.

O segmento da matemática foi composto por uma turma de 20 professores de matemática.

No total foram 118 voluntários, com 98 da área tecnológica e 20 composta pela área matemática. Estas amostras distintas foram escolhidas para oferecer resultados voltados tanto para aspectos funcionais do jogo (usabilidade, layout, questões técnicas) quanto sua utilidade como ferramenta de aula.

\subsection{Testes}

Os testes ocorreram em dois momentos distintos. Durante 15 dias foi realizado um betatest com as duas turmas da computação a fim de expandir o vocabulário do jogo. O teste consistia em fornecer aos voluntários acesso a uma versão preliminar do jogo (que possuía 5 questões de regra de três, sendo 2 de nível fácil e 3 de nível médio) e poucas ações mapeadas. Foi solicitado aos jogadores que tentassem resolver cada problema escrevendo as ações necessárias. Todos os termos foram armazenados para posterior análise e, com isto, o término do protótipo.

Após a coleta dos resultados do beta-test e realizadas as alterações necessárias no jogo, foi feita uma próxima validação em um período de 15 dias. Nesta validação, os voluntários testadores tiveram acesso ao jogo por meio de um link, e ao final, o formulário em formato de questionário a ser preenchido. O jogo continha as mesmas questões de sua versão preliminar acrescido de 2 questões de nível fácil sobre área/perímetro e 2 questões de nível médio sobre ângulos, totalizando assim 9 questões. O próprio jogo continha instruções básicas de seu funcionamento e foi instruído aos voluntários para que efetuassem o cadastro utilizando um nome e selecionassem uma das turmas previamente cadastradas. Os termos digitados pelos voluntários foram analisados a fim de melhorar a interação para com o jogo, cadastrando novas expressões.

Cada jogador preencheu um questionário no final do jogo. Este questionário teve o objetivo de explorar as dificuldades encontradas pelos jogadores, tanto de cunho gramatical (léxico), quanto visual (ergonomia), avaliando o desempenho do jogo, contemplando os aspectos necessários para o entendimento e o bom funcionamento do mesmo.

As questões aplicadas eram de múltipla escolha com graduação de intensidade, sendo 1 a nota mais baixa e 5 a nota mais alta. Ao final do questionário, o jogador pode também dar sugestões de melhoria.

\subsection{Resultados obtidos}

Analisando os termos escritos pelos jogadores, notou-se certo imediatismo por parte dos mesmos. Em diversos desafios os jogadores informaram apenas uma ação, sem estar relacionado a nenhum objeto. Muitas vezes também foi constatado que os jogadores preferiram digitar a resposta numérica diretamente, sem relacionar com as ações pedidas no jogo. Este resultado ocorreu em ambos os testes, sendo necessário após o beta-test efetuar o cadastro dessas expressões (quando coerente com o problema em questão), a fim de melhorar a interatividade. Também no beta-test foi revelada a necessidade de manter um histórico das descrições da sala, este elemento foi adicionado ao protótipo conforme descrito em sua seção correspondente.

Após a leitura dos dados coletados do questionário, constou-se na pesquisa uma grande satisfação por parte dos professores, que afirmaram se tratar de uma ferramenta capaz de 
beneficiar alunos no aprendizado. Porém, os professores também salientaram a necessidade de expandir a quantidade de palavras mapeadas, para serem aceitas pelo jogo, também aumentando a dificuldade e complexidade das questões. A figura 5 apresenta as médias obtidas ao final da aplicação do questionário em todos jogadores.

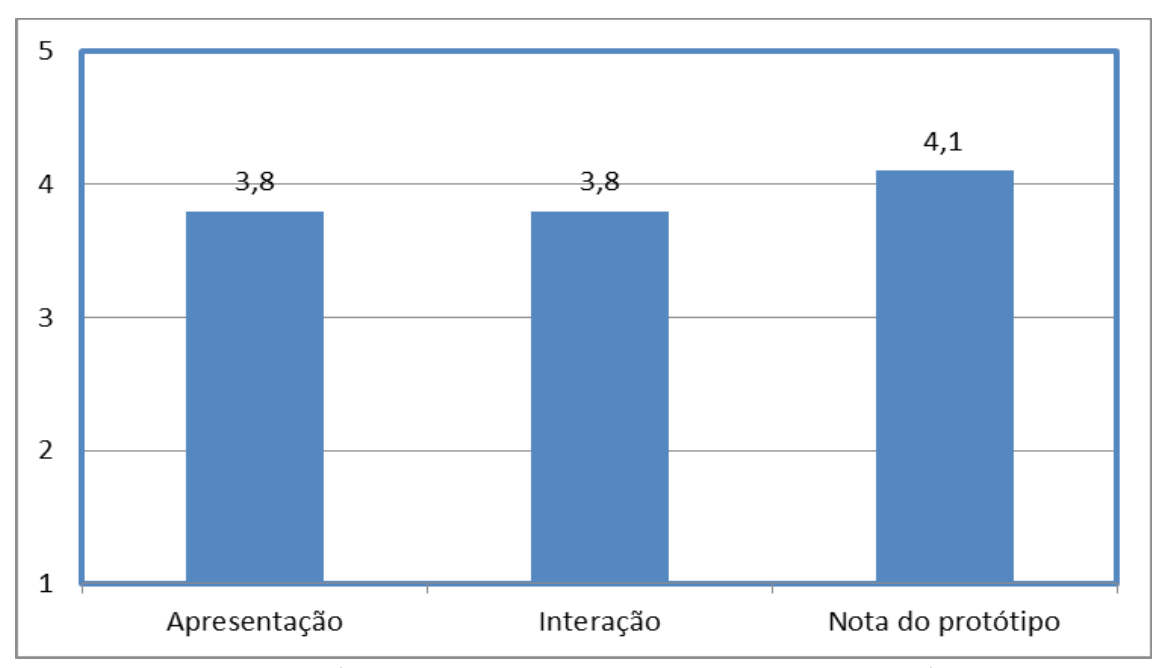

Figura 5 -Médias alcançadas segundo o questionário proposto

Analisando os dados do gráfico pode-se destacar o fato que o jogo foi bem aceito por todos os voluntários testadores, ficando a conclusão que tanto a apresentação quanto os aspectos interativos do jogo são importantes. Destaque também para o fato de que cerca de $80 \%$ dos jogadores encontraram dificuldades ao jogar, apontando a dificuldade em saber o que digitar para resolver o desafio. Percebeu-se nos testes iniciais que os alunos se comportavam de forma imediatista, querendo entender o jogo sem ler as mensagens apresentadas. O objetivo de desenvolver um adventure foi exatamente apresentar aos alunos uma forma mais textual de jogo, onde é preciso que o aluno raciocine sobre o que deve ser digitado para solucionar o problema apresentado.

Por fim, em relação às sugestões dadas ao jogo. Componentes da amostra da computação fizeram sugestões em relação ao funcionamento do jogo, propondo tutoriais, efeitos sonoros e mais animações. Enquanto integrantes da amostra matemática fizeram observações quanto ao conteúdo do jogo, sugerindo novos conteúdos a serem aplicados no jogo.

\section{CONSIDERAÇÕES FINAIS}

Com base nos resultados coletados pode-se concluir que o castelo da matemágica é funcional e seu uso pode ser relevante em sala de aula. Os resultados obtidos nos testes realizados mostraram que a ferramenta é útil no auxílio do ensino, servindo de ferramenta de controle para os professores e ajudando os alunos a aprenderem de forma mais prazerosa.

Como trabalhos futuros, será realizado um trabalho de automatização de cadastro de etapas, onde o próprio professor poderá alimentar o jogo com as etapas válidas para o problema elaborado. Juntamente com essa funcionalidade, está prevista a possibilidade de expansão da ontologia do jogo, o que permitirá a um professor criar seus próprios desafios, adicionar elementos à ontologia e aplicar os desafios em qualquer conteúdo.

Adicionalmente à essas alterações, o relatório de jogadores será melhorado, fornecendo mais informações para que o professor possa analisar seus alunos devidamente. O relatório poderá conter mais informações além do que o aluno escreveu tais como os resultados que recebeu e em que fase ele estava jogando. O cadastro de turma também será melhorado, juntamente com um cadastro de jogadores mais preciso, com informações que forem relevantes para a avaliação. 


\section{REFERÊNCIAS}

ARAÚJO, Iracema. R.de O. A utilização de lúdicos para auxiliar a aprendizagem $\mathbf{E}$ desmistificar o ensino da matemática Florianópolis: UFSC, 2000. Disponível em: < >. Acesso em: 22 de set. 2013.

BITTENCOURT, João Ricardo; GIRAFFA, Lucia Maria. A Utilização dos Role-Playing Games Digitais no Processo de Ensino-Aprendizagem, PUCRS 2003 Disponível em: < http://www3.pucrs.br/pucrs/files/uni/poa/facin/pos/relatoriostec/tr031.pdf > Acesso em 27 set 2013

GRANADE, Stephen 2010, Teaching with interactive fiction: ESL Disponível em < http://brasslantern.org/editorials/teaching-esl.html> acesso em 26 set 2013

GROENWALD, Claudia; TIMM, Ursula."Utilizando curiosidades e jogos matemáticos em sala de aula" Educação matemática em revista. SBEM-RS,p.21-26, nov. 2000.

NICOLETTI, Angelida A. M e FILHO, Raulito R. G. Aprender brincando: a utilização de jogos,brinquedos e brincadeiras como recurso pedagógico. Revista de divulgação técnicocientíficia do ICPG, v.2, n.5, p.91-94, abr/jun. 2004

JERZ, Dennis G. "Jerz's Introduction (Storytelling and Computer Games; UWEC Panel, May 2001) Disponível em < http://jerz.setonhill.edu/if/adams/intro.html $>$ Acesso em 24 set 2013

LIMA, Maria; SOARES, Vanessa; LINS e SILVA, Maria Emília. Jogos educativos no âmbito educacional: um estudo sobre o uso dos jogos no projeto MAIS da rede municipal do Recife. $\quad 2009 . \quad$ Recife, Disponível em: $<$ http://www.ufpe.br/ce/images/Graduacao_pedagogia/pdf/2009.2/jogos\%20educativos\%20no $\% 20$ mbito $\% 20$ educacional $\% 20$ um $\% 20$ estudo $\% 20$ sobre $\% 20 \mathrm{o} \% 20$ uso.pdf $>$.Acesso em: 10 set. 2013

LOPES, Laura M. C.; KLIMICK, Carlos; CASANOVA, Marco A. Relato de uma Experiência de Sistema Híbrido no Ensino Fundamental: Projeto Aulativa, Revista Brasileira de Aprendizagem Aberta e a Distância. Associação Brasileira de Educação à Distância. Online. 2002, vol 1 num 2. Disponível em: http://www.abed.org.br

MORATORI, P. B. Por que utilizar jogos educativos no processo de ensino aprendizagem? Rio de Janeiro: UFRJ, 2003. Disponível em: $<$ http://www.nce.ufrj.br/ginape/publicacoes/trabalhos/t 2003/t 2003 patrick barbosa moratori. pdf>. Acesso em: 22 de set. 2013.

PIERINI, Livia M.;VALENTIM, Maiara A.C. ; CARDOSO Andréa Brinquedos Numéricos: um jogo para o ensino dos conjuntos numéricos Minas Gerais: UFA 2012. Disponível em: < http://www.br-ie.org/pub/index.php/sbie/article/view/1702/1463>. Acesso em: 22 de set. 2013. 